\title{
Parasite-specific Anergy in Human Filariasis Insights after Analysis of Parasite Antigen-driven Lymphokine Production
}

Thomas B. Nutman, V. Kumaraswami, and Eric A. Ottesen

Laboratory of Parasitic Diseases, National Institutes of Health, Bethesda, Maryland 20892; and The Tuberculosis Research Center, Madras, India

\begin{abstract}
The antigen-specific immune unresponsiveness seen in bancroftian filariasis was studied by examining lymphokine production in peripheral blood mononuclear cells (PBMC) or PBMC subpopulations from 10 patients with asymptomatic microfilaremia, 13 patients with elephantiasis and 6 normal North Americans. In each group of patients, the kinetics of the lymphokine response and the response to mitogens and nonparasite antigens did not differ significantly. In marked contrast, when antigeninduced lymphokine production was examined, most patients with microfilaremia were unable to produce either interleukin 2 (IL 2) or $\boldsymbol{\gamma}$-interferon (i.e., were nonresponders), and the few who could (hyporesponders, generally with quite low microfilaremia levels) did so at levels significantly less than those of patients with elephantiasis, all of whom showed strong responses to parasite antigen. Removal of neither adherent cells or $\mathbf{T}+$ cells affected the parasite-specific anergy seen in those with microfilaremia, suggesting a state of $T$ cell tolerance to the parasite in patients with this most common clinical manifestation of bancroftian filariasis.
\end{abstract}

\section{Introduction}

The lymphatic filariases, estimated to affect $\sim 100$ million people (1), are chronic parasitic helminth infections that evoke host immune responses that have been implicated both in resistance to infection $(2,3)$ and in the pathogenesis of the different clinical expressions of these diseases (4). The range of clinical expressions is broad, and in both bancroftian and brugian filariasis these include elephantiasis, "filarial fevers" associated with lymphangitis and lymphadenitis, the syndrome of tropical pulmonary eosinophilia (TPE) ${ }^{1}$ and a condition in which individuals are entirely asymptomatic yet have persistent microfilaremia. This wide range of clinical expression is felt to reflect the diversity of the host's immune response to the filarial parasite (4) and, indeed, these clinical groups can be roughly stratified on the basis of

Address reprint requests to Dr. Nutman, National Institutes of Health, Building 5, Room 112, Bethesda, MD 20892.

Received for publication 16 July 1986 and in revised form 16 October 1986.

1. Abbreviations used in this paper: $\mathrm{AET}, 2$-aminoethylisothiouronium bromide; BmA, Brugia malayi adult antigen; $\mathrm{CP}$, chronic pathology (elephantiasis); $\gamma$-IFN, $\gamma$-interferon; HSA, human serum albumin; HBSS, Hanks' balanced salt solution; IL-2, interleukin 2; MF, asymptomatic microfilaremic; PBMC, peripheral blood mononuclear cells; PPD, purified protein derivative; SI, stimulation index; TPE, tropical pulmonary eosinophilia; TT, tetanus toxoid.

The Journal of Clinical Investigation, Inc.

Volume 79, May 1987, 1516-1523 their immune responsiveness to the parasite or the parasite products (3).

Several observations (5-8) suggest that distinct immunological defects exist in patients with the asymptomatic form of the infection (manifested by parasitemia) that could allow the parasite to survive "unscathed" within the host, thus assuring successful completion of the life cycle as microfilariae are ingested with the blood meal of vector mosquitoes. While quantitative studies of humoral immune responses in patients with filariasis have generally shown hyperglobulinemia with elevated levels of antifilarial antibodies of most isotypes (3), microfilaremic individuals have consistently been found to be a subgroup of patients with relatively low levels of parasite-specific antibody (6). In vitro studies of parasite antigen-driven antibody production by these patients' peripheral blood mononuclear cells (PBMC) have indicated that a parasite-specific B cell tolerance may exist (7). Furthermore, it has been shown that lymphocytes from patients with asymptomatic microfilaremia (associated with either Brugia malayi or Wuchereria bancrofti infections) fail to respond to filarial antigens in cellular proliferation assays though they retain their reactivity to nonparasite antigens $(9,10)$. Serum suppressor factors (9), suppressor adherent cells (assumed to be monocytes) (9), and T-lymphocyte suppressor cells (10) each have been implicated as mediators of this parasitic-specific immunosuppression. More recently, increased numbers of T-suppressor cells resulting in abnormally low $\mathrm{T}$ helper/T suppressor ratios have been described in filaria infected populations; and, reportedly, both of these $T$ cell abnormalities return to normal after successful treatment with diethylcarbamazine (11).

All of these studies have as their basis the notion of strict modulation of the immune response to parasite antigen, but the actual mechanisms underlying this immunomodulation have not been defined. Thus, to study these mechanisms directly, we have examined $\mathrm{T}$ cell responsiveness to parasite antigen (assessed by the measurement of the lymphokines interleukin 2, IL-2, and $\gamma$-interferon, IFN) in patients with asymptomatic microfilaremia and then contrasted the findings to the responses in patients with filariasis manifested by chronic lymphatic pathology. In addition, we have evaluated the possible immunoregulatory effects of suppressor $\mathrm{T}$ cell and adherent cell populations. Our results indicate that microfilaremia is associated with a state of specific $T$ cell anergy, manifested by an inability to generate lymphokine, with respect to parasite antigen. Further, this anergy cannot be overcome by removal of suppressor cell populations. These findings point directly to the concept of an immunologically tolerant state which is parasite specific. Such tolerance is likely important in maintaining the unique biological relationship that exists between the human host and its parasites.

\section{Methods}

Study population. 23 adult volunteers living in the area of Madras, India, where filariasis with periodic $W$. bancrofti is endemic were studied. After 
the purposes and methods of this investigation had been explained, study subjects had a history and physical examination, routine hematologic evaluation, stool examinations to exclude intestinal parasites, and a separate blood examination for circulating microfilariae. On the basis of these findings, each individual was assigned to a clinical category. Determination of the levels of microfilaremia was carried out by filtering $1 \mathrm{ml}$ of heparinized blood obtained between 10 p.m. and 2 a.m. through a 3- $\mu \mathrm{m}$ filter (Nuclepore Co., Pleasanton, CA) and counting the number of parasites on the filter after staining with Giemsa (12). Six normal North Americans (two females, four males) ranging in age between 24 and 44 years were also studied.

Antigens and mitogens. B. malayi adult antigen $(\mathrm{BmA})$ was prepared as a saline extract of adult parasites as described and characterized previously (13). Tuberculin purified protein derivative (PPD) was obtained from Connaught Laboratories (Toronto, Canada). Tetanus toxoid (TT) was obtained from the Massachusetts Public Health Service (Boston, MA). Phytohemagglutinin (PHA) was obtained from Burroughs Wellcome (Research Triangle, NC).

Microfilariae were obtained from the peritoneal cavity of jirds (Meriones unguiculatus) by lavage with $25 \mathrm{ml}$ of sterile Hanks' balanced salt solution (HBSS). Adult worms were removed, and the harvested microfilariae were washed twice with sterile HBSS, centrifuged, and resuspended in C-RPMI (see below). To remove contaminating jird peritoneal inflammatory cells, the microfilarial suspension was incubated in a petri dish for $45 \mathrm{~min}$ at $37^{\circ} \mathrm{C}, 5 \% \mathrm{CO}_{2}$. The nonadherent microfilariae were collected, overlaid on Ficoll-Diatrizoate (Bionetics, Rockville, MD), and centrifuged at 1,750 rpm for $20 \mathrm{~min}$. The microfilariae that sedimented in the pellet were harvested and washed in C-RPMI. Any residual jird erythrocytes were lysed by $\mathrm{NH}_{4} \mathrm{Cl}$ lysis.

Isolation of cell populations. PBMC were collected from heparinized blood drawn mid-morning and were further purified by sedimentation on a Hypaque-Ficoll gradient in a standard fashion (14). The PBMC were placed in plastic petri dishes at a density of $5 \times 10^{6}$ cells per milliliter. After $1 \mathrm{~h}$ incubation at $37^{\circ} \mathrm{C}$, the nonadherent cells were collected, washed, and further purified (see below); the adherent cells were also collected and washed. $T$ cell enriched fractions were obtained by twice rosetting with 2-aminoethylisothiouronium bromide (AET) treated sheep red blood cells as described previously (15). T4 and T8 positive cells were obtained by incubating the AET positive cells with OKT4 and OKT8 (Ortho Pharmaceuticals, Raritan, NJ), respectively, and then rosetting with ox red blood cells coated with goat anti-mouse IgG (BoeringerMannheim, Indianapolis, IN) as described previously (16).

Proliferation assays. PBMC or subpopulations were cultured at 1 $\times 10^{5}$ cells $/ 0.2 \mathrm{ml}$ in round bottomed 96-well microtiter plates in RPMI 1640 (Biofluids, Rockville, MD) containing 5\% fetal bovine serum (FBS), gentamicin $80 \mu \mathrm{g} / \mathrm{ml}$, and $25 \mu \mathrm{M}$ Hepes (C-RPMI). To the wells were added media, BmA (over a range from 0.01 to $10 \mu \mathrm{g} / \mathrm{ml}$ ), PPD (10 $\mu \mathrm{g} / \mathrm{ml})$ or the mitogen PHA $(10 \mu \mathrm{g} / \mathrm{ml})$. All cultures were performed in triplicate and maintained in a humidified atmosphere at $37^{\circ} \mathrm{C}$ with $5 \% \mathrm{CO}_{2}$.

After $3 \mathrm{~d}$ (for mitogens) or $5 \mathrm{~d}$ (for antigens), $20 \mu \mathrm{l}$ of C-RPMI containing $1 \mu \mathrm{Ci}\left[{ }^{3} \mathrm{H}\right]$ thymidine (New England Nuclear, Boston, MA) was added to the cultures and the cells were collected on glass filters after $16 \mathrm{~h}$ with a Mash cell harvester (M. A. Bioproducts, Walkersville, MD). The incorporation of thymidine was measured by liquid scintillation spectroscopy. Data are expressed as the stimulation index (SI) obtained by dividing the counts per minute (mean of triplicate cultures) of the antigen or mitogen stimulated cultures by the mean counts per minute of the control cultures.

Culture conditions for lymphokine production. Cultures for the production of IL-2 and $\gamma$-IFN were performed in C-RPMI in 24 well tissue culture plates (Costar, Cambridge, MA). These cultures contained 2 $\times 10^{6}$ cells per $\mathrm{ml}$ (PBMC or subpopulations with $5 \%$ adherent cells) and were incubated either with media alone or with BmA, PPD, or PHA at a final concentration of $10 \mu \mathrm{g} / \mathrm{ml}$. Cultures were set up in replicates, and supernatant fluid from duplicate wells were harvested at 24,48 , and $120 \mathrm{~h}$ and stored at $-70^{\circ} \mathrm{C}$ until assayed.

In one set of experiments (see below) IL- 2 and $\gamma$-IFN containing supernatants were derived from PHA-stimulated PBMC. These supernatants were then incubated with media alone or with Sepharose coupled to either human serum albumin (HSA) or BmA at $50 \% \mathrm{vol} / \mathrm{vol}$ for 24 $h$ with rotation. The supernatants were harvested after centrifugation and assessed for lymphokine activity.

Assays for IL-2 and $\gamma-I F N$. IL-2 was measured using the IL-2 dependent HT-2 cell line as described previously (17). Data for IL-2 are expressed in International Units, $1 \mathrm{U}$ being the IL-2 concentration necessary to obtain half maximal incorporation of $\left[{ }^{3} \mathrm{H}\right]$ thymidine by the HT- 2 cells in a standard assay. $\gamma$-IFN activity was determined by the reduction in vesicular stomatitis virus plaque formation on human amnion (WISH) cells grown in microtiter plates (18). The antiviral activity, expressed in IFN units, was calculated as the reciprocal of the highest dilution of the sample that reduced the number of viral plaques by $50 \%$.

Micro enzyme linked immunosorbent assay (ELISA) for parasitespecific IgG. IgG antifilarial antibodies were measured using an ELISA as described (19). All results are expressed as end titers all run within the same assay.

\section{Results}

Study population. 13 individuals with chronic lymphatic obstruction (CP) and 10 with asymptomatic microfilaremia (MF) were studied. Relevant demographic, parasitological and clinical data are summarized in Table I. There were no significant differences between the patient groups with regard to sex or age distribution. None of the patients with microfilaremia had symptoms referrable to filariasis. In addition, those patients with microfilaremia had a rather broad range of numbers of circulating microfilariae. Their geometric mean antifilarial antibody level was 746 (compared to 2,409 for the patients with $C P ; P<0.01$ ). Further, none of the patients with MF were able to mount a proliferative response (SI $>2$ ) to the filarial parasite antigen, BmA.

Kinetics of antigen- and mitogen-driven IL-2 and $\gamma-I F N$ production. After defining in preliminary experiments the antigen and mitogen concentration stimulating lymphokine production optimally (data not shown), we examined the kinetics of IL-2 and $\gamma$-IFN in response to parasite antigen (Fig. 1). When patient PBMC were stimulated with the filarial parasite antigen BmA and the supernatant fluid tested sequentially for lymphokine levels, antigen-driven IL-2 production was found to peak by 48 $\mathrm{h}$, whereas $\gamma$-IFN rose rapidly for $48 \mathrm{~h}$ and then more slowly for all $5 \mathrm{~d}(120 \mathrm{~h})$. Since the time course of mitogen (PHA)driven IL- 2 and $\gamma$-IFN production paralleled that of the antigen stimulated cultures, subsequent IL- 2 and $\gamma$-IFN data are derived from supernatants harvested from 2-d and 5-d cultures, respectively. Further, the kinetics of both antigen- (including PPD, TT) and mitogen-driven lymphokine production were similar for all groups studied (data not shown).

Spontaneous IL-2 and gamma-IFN production in human filariasis. Spontaneous lymphokine production was first examined in PBMC from all of the patients in the study population and in the North American controls. Very few patients with either form of filariasis produced measurable amounts of either IL-2 or $\gamma$-IFN in unstimulated cultures. $1 / 10$ patients with MF, $2 / 13$ patients with $\mathrm{CP}$, and $0 / 6$ North Americans had spontaneous IL-2 production; these same three patients also produced $\gamma$-IFN spontaneously (data not shown).

Lymphokine production in response to parasite antigen, nonparasite antigen, and mitogen. All of the patients (both those with microfilaremia and those with chronic pathology) were able to produce IL-2 and $\gamma$-IFN in response to PHA (Fig. 2), with 


\begin{tabular}{|c|c|c|c|c|c|c|c|c|}
\hline \multirow[b]{3}{*}{ Patient No. } & \multirow[b]{3}{*}{ Diagnosis } & \multirow[b]{3}{*}{ Age/Sex } & \multirow[b]{3}{*}{$\begin{array}{l}\text { Microfilariae } \\
\text { No. }\end{array}$} & \multirow[b]{3}{*}{ Eosinophils } & \multirow[b]{3}{*}{$\begin{array}{l}\text { Antifilarial } \\
\text { antibody titer }\end{array}$} & \multicolumn{3}{|c|}{ Lymphocyte proliferation } \\
\hline & & & & & & \multirow[b]{2}{*}{ Medium } & \multicolumn{2}{|l|}{$\mathrm{SI}^{*}$} \\
\hline & & & & & & & BMA & PPD \\
\hline & & & $M f / m l$ & $\operatorname{Eos} / \mathrm{mm}^{3}$ & & $c p m$ & & \\
\hline 1 & $\mathrm{CP}$ & $45 / M$ & 0 & 1,980 & 3,200 & 2,695 & 3.6 & 2.5 \\
\hline 2 & $\mathrm{CP}$ & $35 / \mathrm{M}$ & 0 & 560 & 1,600 & 1,335 & 3.4 & 3.2 \\
\hline 3 & $\mathrm{CP}$ & $51 / \mathrm{M}$ & 0 & 240 & 800 & 1,274 & 3.1 & 7.9 \\
\hline 4 & $\mathrm{CP}$ & $52 / \mathrm{M}$ & 0 & 300 & 1,600 & 1,879 & 3.2 & 9.0 \\
\hline 5 & $\mathrm{CP}$ & $71 / \mathrm{M}$ & 0 & 160 & 3,200 & 6,504 & 3.3 & 6.7 \\
\hline 6 & $\mathrm{CP}$ & $28 / F$ & 0 & 1,800 & 6,400 & 5,036 & 3.2 & 2.7 \\
\hline 7 & $\mathrm{CP}$ & $30 / \mathrm{F}$ & 0 & 280 & 6,400 & 6,102 & 3.2 & 2.2 \\
\hline 8 & $\mathrm{CP}$ & $55 / F$ & 0 & 252 & 3,200 & 1,605 & 3.0 & 2.8 \\
\hline 9 & $\mathrm{CP}$ & $40 / \mathrm{M}$ & 0 & 290 & 1,600 & 2,106 & 4.2 & 3.3 \\
\hline 10 & $\mathrm{CP}$ & $36 / \mathrm{M}$ & 0 & 900 & 1,600 & 1,844 & 5.2 & 4.8 \\
\hline 11 & $\mathrm{CP}$ & $25 / \mathrm{F}$ & 0 & 1,232 & 3,200 & ND & ND & ND \\
\hline 12 & $\mathrm{CP}$ & $42 / \mathrm{M}$ & 0 & 720 & 12,800 & ND & ND & ND \\
\hline 13 & $\mathrm{CP}$ & $25 / \mathrm{M}$ & 0 & 640 & 3,200 & ND & ND & ND \\
\hline 14 & MF & $32 / \mathrm{F}$ & 180 & 0 & 800 & 1,751 & 1 & 3.2 \\
\hline 15 & MF & $28 / \mathrm{M}$ & 1 & 162 & 800 & 8,590 & 1 & 3.72 \\
\hline 16 & MF & $41 / F$ & 5 & 300 & 400 & 2,184 & 1.2 & 4.9 \\
\hline 17 & MF & $52 / \mathrm{M}$ & 10 & 280 & 800 & 4,186 & 1.3 & 2.15 \\
\hline 18 & MF & $27 / \mathrm{M}$ & 30 & 1,260 & 800 & 3,190 & 1 & 6.8 \\
\hline 19 & MF & $39 / \mathrm{M}$ & 65 & 1,000 & 400 & 1,695 & 1.5 & 5.2 \\
\hline 20 & MF & $25 / F$ & 300 & 200 & 1,600 & ND & ND & ND \\
\hline 21 & MF & $58 / \mathrm{M}$ & 35 & 210 & 800 & ND & ND & ND \\
\hline 22 & MF & $21 / \mathrm{M}$ & 200 & 0 & 1,600 & ND & ND & ND \\
\hline 23 & MF & $35 / F$ & 20 & 114 & 400 & ND & ND & ND \\
\hline
\end{tabular}

* Optimal stimulation index - a full dose response was done to BmA (from $0.01 \mu \mathrm{g} / \mathrm{ml}$ to $20 \mu \mathrm{g} / \mathrm{ml}$ ) and two concentrations were used for PPD (1 and $10 \mu \mathrm{g} / \mathrm{ml}$ ). The stimulation index calculated at each antigen concentration and the maximal SI is given for each patient. The medium control is included as a point of reference.

no significant difference in the ability to generate lymphokine between these two groups. Furthermore, when responses to PPD were examined, $7 / 13$ patients with $C P$ and $6 / 10$ patients with microfilaremia showed IL-2 production, while all of the patients with $\mathrm{CP}$ and $8 / 10$ with microfilaremia generated $\gamma$-IFN in response to PPD. Of note is that only one of the nonresponding (to PPD) microfilaremic patients was a non-responder to $\mathrm{BmA}$ (see below).

However, lymphokine production in response to $\mathrm{BmA}$ was different (Fig. 3). All patients with $\mathrm{CP}$ were able to generate both IL-2 and $\gamma$-IFN in response to parasite antigen (BmA), but most $(6 / 10)$ of the patients with microfilaremia were unable to generate one or both lymphokines (IL-2 and $\gamma$-IFN) when stimulated similarly. Thus, for both IL- 2 and $\gamma$-IFN, patients with CP produced significantly more IL-2 $(P<0.05)$ and $\gamma$-IFN $(P$ $<0.01)$ than patients with asymptomatic microfilaremia. Interestingly, the microfilariae levels in those microfilaremic patients who did respond to $\mathrm{BmA}$ were among the lowest of the group (patient numbers 15, 16, 18, and 23 in Table I), and the levels of lymphokine produced after BmA stimulation were signifcantly less than those generated by the same patients in response to PPD.

The effect of parasite antigen on lymphokine production in uninfected individuals. To assure that the BmA stimulated lymphokine production was indeed antigen-specific, the effect of parasite antigen on cells obtained from normal individuals was examined (Table II). Parasite antigen was unable to induce IL2 or $\gamma$-IFN production in 6 uninfected North American individuals studied, but each patient (all previously immunized to TT) was able to produce both IL-2 and $\gamma$-IFN when stimulated with TT.

The effect of parasite antigen or living parasites on lymphokine determination. To exclude the possibility that parasite antigen, by itself, could influence the amount of IL-2 and $\gamma$-IFN measured in supernatant fluid, IL-2 and $\gamma$-IFN containing supernatants were incubated with immobilized BmA (or immobilized HSA as a control), and the lymphokine concentrations quantified (Table III). The parasite antigen had no effect on the concentration of IL- 2 or $\gamma$-IFN detected in these supernatants. Furthermore, when BmA $(10 \mu \mathrm{g} / \mathrm{ml})$ was assayed for intrinsic IL-2 or $\gamma$-IFN, there was no lymphokine activity found associated with the antigen preparation (data not shown).

To assess if microfilariae or their products (excretory/secretory products) interfered with the lymphokine assays, live microfilariae were added at varying concentrations (up to 100 times the maximum concentration found in the peripheral circulation of the study population) to lymphokine containing supernatants. The mixture was incubated for $24 \mathrm{~h}$ and then the supernatant assayed for IL-2 and $\gamma$-IFN. As seen in Table IV, even at the highest concentration, there was no significant effect of the live 

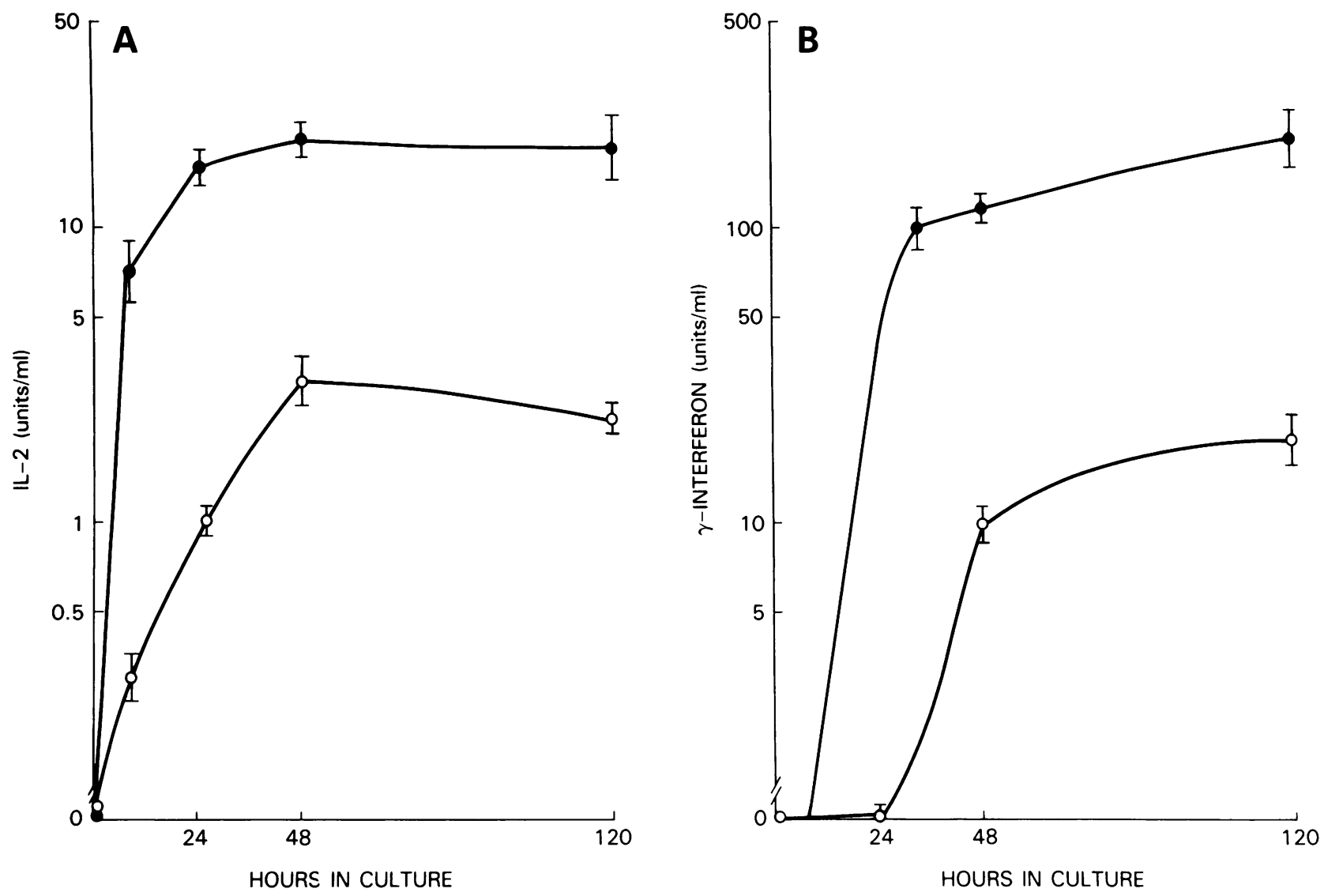

Figure 1. The kinetics of BmA antigen- (open circles) and PHA mitogen-driven (closed circles) IL-2 and $\gamma$-IFN production in patients with filariasis. The time course of the production of both IL-2 $(A)$ and $\gamma$-IFN $(B)$ in 6 patients with chronic lymphatic obstruction is shown. The points represent the mean $\mathrm{U} / \mathrm{ml} \pm \mathrm{SEM}$ of all patients studied.

microfilariae (and presumably their released products) on the measurement of either IL- 2 or $\boldsymbol{\gamma}$-IFN.

The effect of monocyte or T8 depletion on antigen-stimulated lymphokine production. To define the mechanism of the antigen- specific T-cell unresponsiveness, we examined the blood of patients with asymptomatic microfilaremia for evidence of suppressor cells which could inhibit the response to BmA. Since excess numbers of $\mathrm{OKT}^{+}$cells in microfilaremic individuals

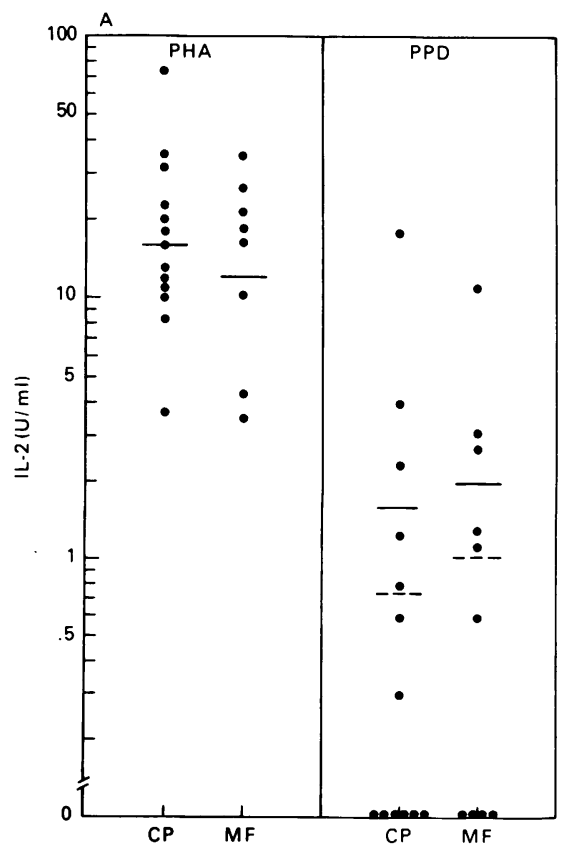

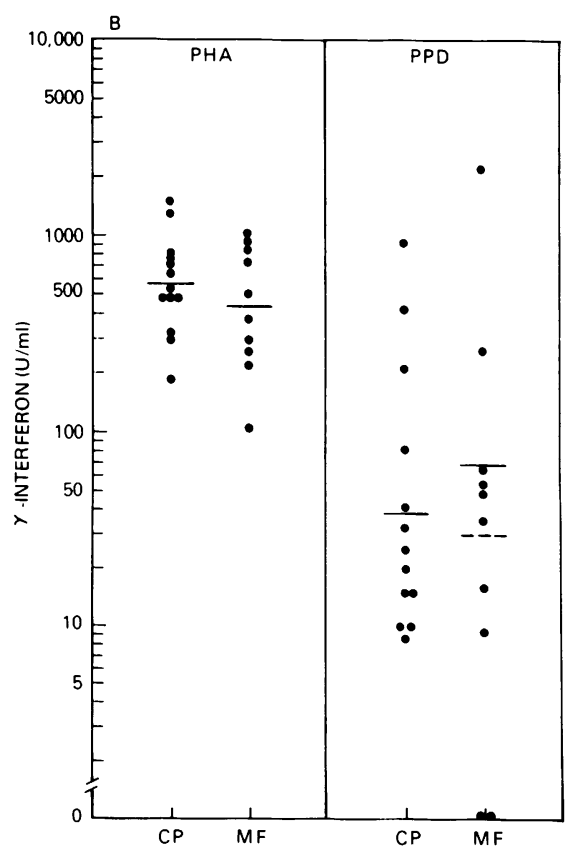

Figure 2. Lymphokine production (A: IL-2; $B$ : $\gamma$-IFN) to mitogen and nonparasite antigen in human filariasis. Each dot represents an individual patient. The solid horizontal lines represent the geometric means of only those who responded; the dashed lines represent the geometric means when all patients were considered. 


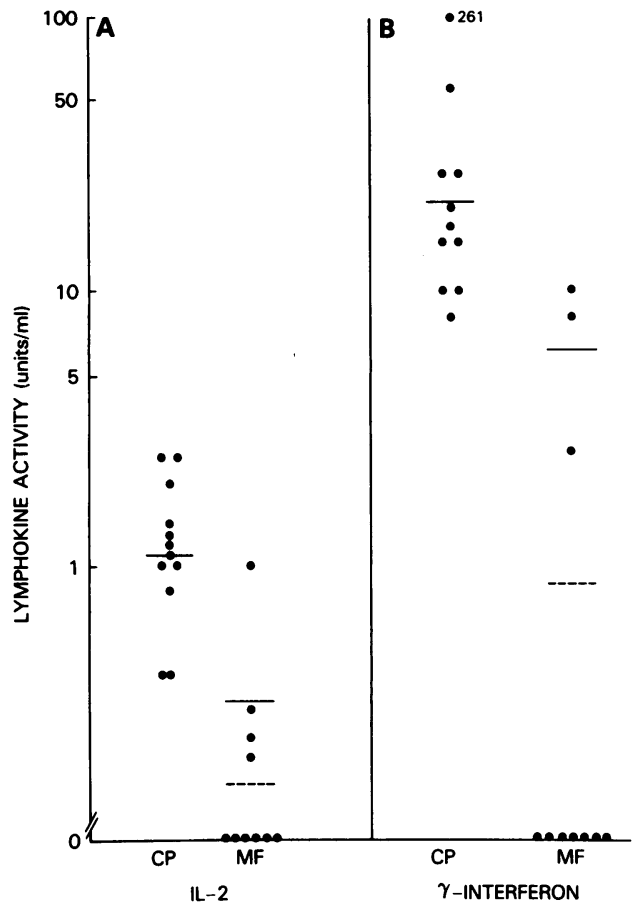

Figure 3. Parasite antigen-driven lymphokine production in patients with filariasis. IL-2 $(A)$ and $\gamma$-IFN $(B)$ production in patients from both clinical categories. Each dot represents an individual patient. The solid horizontal lines represent the geometric means of only those who responded; the dashed lines represent the geometric means when all patients were considered.

had been reported previously (10), the effect of such cells in suppression of the lymphokine response to parasite antigen was sought. The effect of depletion of OKT $8^{+}$cells on the IL-2 response to BmA was studied in all 10 microfilaremic patients and the effect on the $\gamma$-IFN response was evaluated in six. None showed any significant enhancement of the lymphokine response either to BmA (Table V) or to PPD (data not shown) after OKT8 ${ }^{+}$ cell depletion.

An effort to detect suppressor monocytes in the mixed PBMC was made by depletion of these adherent cells on plastic dishes. Three patients with asymptomatic microfilaremia were studied in this fashion, and no change in IL-2 production was found (Fig. 4). Interferon production was not studied. It is interesting, however, that these same patients did show enhancement of

Table II. Effect of Parasite Antigen on Lymphokine Production in Normal Individuals*

\begin{tabular}{lllc}
\hline Number normals & Antigen & IL-2 & $\gamma$-IFN \\
\hline \multirow{3}{*}{6} & & $U / m l$ & $U / m l$ \\
& None & $0 \pm 0$ & $0 \pm 0$ \\
& BmA & $0 \pm 0$ & $0 \pm 0$ \\
& TT & $1.3 \pm .15$ & $4.5 \pm 2.6$ \\
& & & \\
\hline
\end{tabular}

* PBMC of six normal North Americans were cultured in the presence of media, BmA $(10 \mu \mathrm{g} / \mathrm{ml})$ or TT $(0.6 \mu \mathrm{g} / \mathrm{ml})$ and the supernatants were collected and assayed for IL-2 (48 h) and $\gamma$-IFN (120 h). Data are expressed as the mean \pm SE.
Table III. The Effect of Parasite Antigen on Lymphokine Determination

\begin{tabular}{lll}
\hline & IL-2* & $\gamma$-IFN \\
\hline Medium & 8.3 & 14 \\
BmA-Sepharose & $8.1(98 \%)$ & $13.8(99 \%)$ \\
HSA-Sepharose & $8.5(102 \%)$ & $12.6(96 \%)$ \\
\hline
\end{tabular}

* A supernatant containing IL-2 and $\gamma$-IFN was incubated alone, with BmA or HSA coupled to Sepharose for $24 \mathrm{~h}$ with rotation. The supernatants were collected and assayed for lymphokine. The data are expressed as the units per milliliter (percentage of the control [media alone]).

their responsiveness to PPD after such adherent cell depletion. These two findings suggest that the parasite-specific anergy to filarial antigen cannot be reversed by removing these two suppressor cell populations (at least by the methods used) and that other mechanisms for this phenomenon must be considered.

\section{Discussion}

Specific hyporesponsiveness of $\mathrm{T}$ cells to filarial parasite antigens is well documented in the microfilaremic form of infection with the filarial parasites, $W$. bancrofti and B. malayi. It is manifested as variable skin test (delayed type hypersensitivity) responses to microfilarial antigens (20) as well as an absence of $T$ cell proliferation in vitro $(5,9,10)$. However, patients exhibit responsiveness to mitogens and to other soluble antigens, regardless of their inability to respond to the soluble parasite antigen BmA. There have been recent observations suggesting that this immunological hyporeactivity is a result of active immunosuppression by either suppressor $\mathrm{T}$ lymphocytes (11) or monocytes (9), though direct evidence for these cells causing immunomodulation has been limited.

As lymphocyte blastogenic responses are merely reflections

Table IV. The Effect of Living Microfilariae on Lymphokine Determination

\begin{tabular}{lll}
\hline \multicolumn{1}{l}{ Supernatant } & IL-2* & $\gamma$-IFN \\
\hline Medium & $4.48(3.94-6.52)$ & $16.25(12.50-19.49)$ \\
Microfilariae & & \\
$37,000 / \mathrm{ml}$ & $3.63(2.96-4.72)^{\ddagger}$ & $17.78(13.48-23.44)$ \\
$18,500 / \mathrm{ml}$ & $4.74(4.22-5.68)$ & $15.49(9.77-24.54)$ \\
$9,250 / \mathrm{ml}$ & $4.57(3.77-5.52)$ & $16.03(11.88-23.17)$ \\
$4,625 / \mathrm{ml}$ & $3.46(2.99-4.10)$ & $15.96(12.67-20.09)$ \\
$2,312 / \mathrm{ml}$ & $4.29(3.42-5.30)$ & $15.14(11.75-20.42)$ \\
$1,156 / \mathrm{ml}$ & $4.58(4.10-5.78)$ & $18.03(13.74-23.66)$ \\
$575 / \mathrm{ml}$ & $3.43(3.01-3.91)$ & $15.92(12.65-20.05)$ \\
$289 / \mathrm{ml}$ & $3.46(3.53-4.37)$ & $14.9(11.84-18.76)$
\end{tabular}

* Microfilariae were added in decreasing concentrations to supernatants containing IL-2 and $\gamma$-IFN and incubated for $24 \mathrm{~h}$ at $37^{\circ} \mathrm{C}, 5 \%$ $\mathrm{CO}_{2}$. The supernatants were then collected and assayed for IL-2 and $\gamma$-IFN.The data are expressed as the geometric mean units/milliliter (95\% confidence interval).

${ }^{\ddagger}$ All values not significantly different from medium control value. 
Table V. Effect of Removing OKT8+T Cells on the Parasite-antigen Driven Lymphokine Production in Patients with Microfilaremia

\begin{tabular}{|c|c|c|c|c|}
\hline \multirow[b]{2}{*}{ Patient No. } & \multicolumn{2}{|l|}{ IL-2 } & \multicolumn{2}{|l|}{$\underline{\gamma \text {-IFN }}$} \\
\hline & AET+ & OKT8 depleted & AET+ & OKT8 depleted \\
\hline & $U / m l$ & $U / m l$ & $U / m l$ & $U / m l$ \\
\hline 14 & 0 & 0 & 0 & 0 \\
\hline 15 & 1.05 & 0.9 & 10 & 8 \\
\hline 16 & 0.3 & 0.3 & 3 & 2.8 \\
\hline 17 & 0 & 0 & 0 & 0 \\
\hline 18 & 0.2 & 0.4 & 8 & 11 \\
\hline 19 & 0 & 0 & 0 & 0 \\
\hline 20 & 0 & 0 & ND & ND \\
\hline 21 & 0 & 0 & ND & ND \\
\hline 22 & 0 & 0 & ND & ND \\
\hline 23 & 0.2 & 0.15 & ND & ND \\
\hline
\end{tabular}

of the total PBMC population's ability to respond proliferatively regardless of which subpopulation initiates the proliferative response, the present study examined more directly the $\mathrm{T}$ cell dependent mechanisms of immune responsiveness to parasite antigen of both patients with chronic disease and those with asymptomatic microfilaremia. In this regard, when lymphokine production (either IL-2 or $\gamma$-IFN) was examined, one could see evidence for strict $\mathrm{T}$-cell unresponsiveness to parasite antigen in most patients who were clinically asymptomatic despite high levels of circulating microfilariae. These findings contrasted with those from patients with chronic lymphatic obstruction whose $\mathrm{T}$ cells, without exception, were able to produce lymphokines after stimulation with filarial antigen. This observation lends further support to the hypothesis that the host immune response

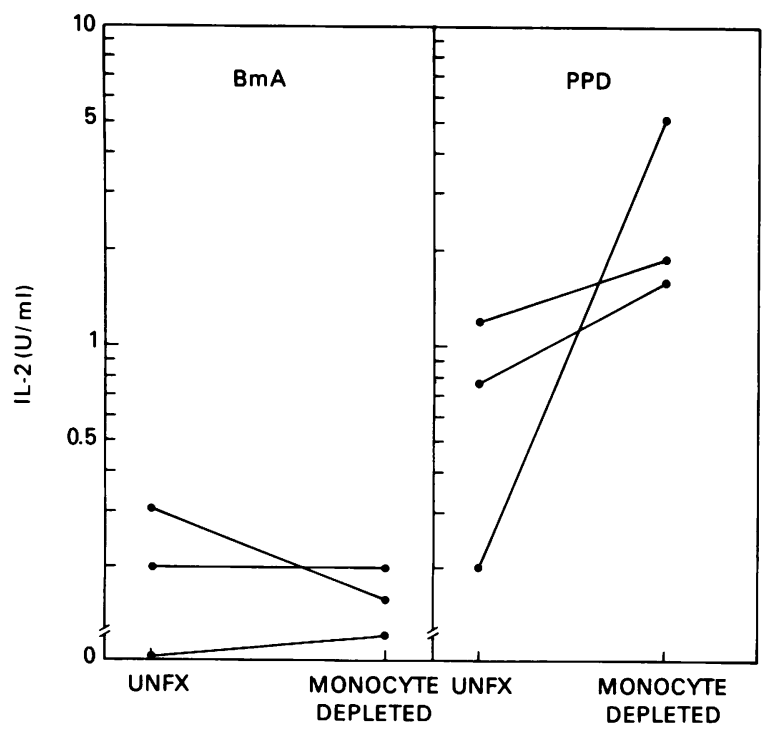

Figure 4. The effect of monocyte depletion on antigen-driven IL-2 production in microfilaremic filariasis. IL-2 production in response to BmA (left) and PPD (right) in unfractionated (UNFX) or monocyte depleted cell populations. Each pair of closed circles represents an individual with microfilaremia. is important in the pathogenesis of the manifestations of chronic disease. Additionally, the present study identifies an intermediate group of patients who tend to be parasite-antigen hyporesponders in contrast to nonresponding microfilaremic individuals and the fully responsive amicrofilaremic patients (CP).

Although there have been isolated reports of defective lymphokine production in several parasitic protozoal diseases of humans such as visceral leishmaniasis (21) and malaria (22) as well as the mycobacterial disease leprosy (the lepromatous form [23]), our findings extend to the multicellular helminth organisms the idea that the host-parasite interaction at an immunological level is likely responsible for the clinical outcome of the infection. Most intriguing remains the observation that it is the state of microfilaremia that is associated with the parasite-specific anergy seen. Since both parasites and circulating soluble parasite antigens can be detected in these hyporeactive patients $(24,25)$, their contribution must be taken into account in terms of immunoregulation. Though it is well established that sera from microfilaremic patients or animals can inhibit cell adherence and in vitro cytotoxicity to microfilariae (26), whether the responsible immunomodulatory factors are parasite-derived remains to be elucidated. While circulating parasite antigens have been identified in the serum of some amicrofilaremic as well as all microfilaremic individuals, their chemical nature remains unclear. However, there has been some recent suggestion that these parasite antigens have immunosuppressive effects on some mitogen-driven immune responses (Piessens, W. F., personal communication). Of even greater interest, however, is the possibility that parasite-specific tolerance is induced by transplacental transfer of microfilariae or other parasite antigens from infected mothers. Though not direct evidence, work done on the phenomenon of sensitization in utero has indicated that antifilarial antibodies of isotypes that do not cross the placenta (e.g., IgE and IgM) have been found in the cord blood of approximately half of the babies born of infected mothers (27) or in the cord sera of several babies born in a region endemic for $W$. bancrofti (28). Thus, for a group of individuals, the environmental factors surrounding their birth may be of critical importance in determining how or whether they subsequently respond to filarial infection.

Our findings in the asymptomatic microfilaremic patients help clarify the deficiencies already described in the parasite antigen-induced cell-mediated immune responses of these individuals. Peripheral blood T cells from amicrofilaremic patients with chronic lymphatic obstruction (CP) proliferated and released IL-2 and $\gamma$-IFN in response to BmA in vitro, whereas patients judged to be asymptomatic and microfilaremic fell into two discrete groups. The majority $(6 / 10)$ were unable to generate any demonstrable lymphokine response (nonresponders) whereas the remainder were hyporesponders. This situation is analogous to findings in lepromatous leprosy where antigen-specific non- and hyporesponders actually reflect two different subpopulations of patients (29). Further, these kinds of observations may help to account for the variety of clinical conditions seen in lymphatic filariasis and also lend validity to the notion that the clinical manifestations of this condition are on a continuum from entirely asymptomatic to extremely symptomatic.

More importantly, the experiments in which specific cell populations were depleted indicated that the parasite specific anergy seen among the patients with asymptomatic microfilaremia could not be overcome by the removal of either OKT8+ T cells or monocytes. While OKT8+ cells in some pathological 
states such as systemic lupus erythematosus (SLE) (30) and perhaps some forms of leprosy (23) have been shown to regulate IL-2 and thereby $\gamma$-IFN production, a significant body of data points to a more complex immunoregulatory network than merely OKT4/OKT8 interactions. The present study as well as one study performed on patients with the lepromatous form of leprosy (29) indicate that the OKT8+ population alone is not responsible for the nonresponsive state seen among these patient groups. In view of the recent reports regarding OKT4+ subpopulations with different functions, perhaps examining the role of the $2 \mathrm{H} 4+$ cells $(31)$ as an inducer of suppression for the antigendriven $\mathrm{T}$ cell responses in microfilaremia should be an important further study. Also, as Leu7+ cells have been shown to regulate lymphokine production in certain disease states (e.g., SLE [30]), the role of this cell population in lymphatic filariases remains to be evaluated.

Monocyte suppressor activity also appears not to explain the parasite antigen-specific anergy in our microfilaremic patients since monocyte suppression could be demonstrated only for the response to PPD and not at all for the response to BmA. Thus, it is still unclear what the controlling factors involved in the immunological reactivity to parasite antigen really are, whether exogenous suppressor mechanisms or endogenous antigen tolerance.

Epidemiological studies in areas where filariasis is endemic have revealed differential susceptibilities to infection both within the entire population as well as within families studied. Though the potential immunologic cause of this difference in susceptibility has not been investigated except for one study in mice (32) and one in man (33), work done with filaria-specific $T$ cell clones (19) as well as with other parasites has implicated in part the major histocompatibility complex (MHC). The specific involvement of the MHC loci in regulating the host response in lymphatic filariasis is currently being evaluated.

Finally, this study clearly indicates the usefulness of looking beyond lymphocyte proliferation when evaluating immunoregulatory issues in diseases such as filariasis. While our observations do not provide information on the induction of a tolerant state in filarial parasitic infections, studies carried out with $T$ cells from patients with influenza virus infection (34) point to the possibility that in vitro models for immune tolerance to any infectious pathogen may be developed. With these and other tools, the regulatory aspects of the immune responses to parasites and parasite antigen should be able to be dissected so that possible targets can be identified for modulating the host response and, thus, the nature of disease in filaria-infected individuals.

\section{Acknowledgments}

The authors wish to thank Dr. David Volkman for his helpful input at the beginning of this study, the staff of the Tuberculosis Research Center (particularly Dr. P. R. Narayanan) for their valuable support, and the NIAID/LPD editorial staff for their help in the preparation of this manuscript. This project was carried out as part of the Indo-U. S. Science and Technology Initiative.

\section{References}

1. WHO Expert Committee on Filariasis. 1984. Fourth Report World Health Organization Technical Report. Serial No. 702.

2. McGreevy, P. B., S. Ratiwayanto, S. Tuti, M. McGreevy, and D. T. Dennis. 1980. Brugia malayi: relationship between antisheath an- tibodies and amicrofilaremia in natives living in an endemic area of South Kalimantan, Borneo. Am. J. Trop. Med. Hyg. 29:553-562.

3. Ottesen, E. A. 1980. Immunopathology of lymphatic filariasis in man. Springer Semin. Immunopathol. 2:373-385.

4. Ottesen, E. A. Immunological aspects of lymphatic filariasis and onchocerciasis in man. 1984. Trans. R. Soc. Trop. Med. Hyg. 78:9-18.

5. Ottesen, E. A., P. F. Weller, and L. Heck. 1977. Specific cellular immune unresponsiveness in human filariasis. Immunology. 33:413421.

6. Piessens, W. F., P. B. McGreevy, P. W. Piessens, M. McGreevy, I. Koiman, H. S. Saroso, and D. T. Dennis. 1980. Immune responses in human infections with Brugia malayi. Specific cellular unresponsiveness to filarial antigens. J. Clin. Invest. 65:172-179.

7. Nutman, T. B., V. Kumaraswami, and E. A. Ottesen. 1985. Specific $B$ and $T$ cell immune unresponsiveness in human lymphatic filariasis. Clin. Res. 33(2):383. (Abstr.)

8. Ottesen, E. A., P. F. Weller, M. Lunde, and R. Husssain. 1982. Endemic filariasis on a Pacific Island. II. Immunological aspects: immunoglobulin, complement, and specific antifilarial IgG, IgM and IgE antibodies. Am. J. Trop. Med. Hyg. 31:953-961.

9. Piessens, W. F., S. Ratiwaytano, S. Tuti, J. H. Palmieri, P. W. Piessens, I. Koiman, and D. T. Dennis. 1980. Antigen-specific suppressor cells and suppressor factors in human filariasis with Brugia malayi. $N$. Engl. J. Med. 307:144-148.

10. Piessens, W. F., F. Partono, S. L. Hoffman, S. Ratiwayanto, P. W. Piessens, J. R. Palmieri, I. Koiman, and D. T. Dennis. 1982. Antigen-specific suppressor $\mathrm{T}$ lymphocytes in human lymphatic filariasis. N. Engl. J. Med. 307:144-148.

11. Piessens, W. F., S. L. Hoffman, S. Ratiwayanto, P. W. Piessens, F. Partono, L. Kurniawan, and H. A. Marwoto. 1983. Opposing effects of filariasis and chronic malaria on immunoregulatory $\mathrm{T}$ lymphocytes. Diagn. Immunol. 1:257-260.

12. Weller, P. F., and E. A. Ottesen. 1978. Failure of diethylcarbamazine as a provocative test in subperiodic Wuchereria bancrofti filariasis. Trans. R. Soc. Trop. Med. Hyg. 7:31-32.

13. Hussain, R., R. Hamilton, V. Kumaraswami, N. F. Adkinson, and E. A. Ottesen. 1981. IgE responses in human filariasis. I. Quantitation of filaria-specific IgE. J. Immunol. 127:1623-1629.

14. Boyum, A. 1968. Separation of leukocytes from blood and bone marrow. Scand. J. Clin. Lab. Invest. 21(Suppl. 97):77-89.

15. Falkoff, R., M. Peters, and A. S. Fauci. 1983. T cell enrichment and depletion of human peripheral blood mononuclear cell preparations. Unexpected findings in the study of the functional activities of the separated populations. J. Immunol. Methods. 50:39-49.

16. Le thi Bich-Thuy, H. C. Lane, and A. S. Fauci. 1985. Human B cell proliferation in response to recombinant interleukin 2 is not due to T cell help. Cell. Immunol. 94:353-359.

17. Watson, J. 1979. Continuous proliferation of murine antigenspecific helper T-lymphocytes in culture. J. Exp. Med. 150:1510-1516.

18. Stewart, W. D. 1981. The Interferon System. Springer-Verlag, New York. Second ed. 13-24.

19. Nutman, T. B., E. A. Ottesen, A. S. Fauci, and D. J. Volkman. 1984. Parasite antigen-specific $T$ cell lines and clone: major histocompatibility complex restriction and B cell helper function. J. Clin. Invest. 73:1754-1762.

20. Weller, P. F., E. A. Ottesen, and L. Heck. Immediate and delayed hypersensitivity skin test responses to the Dirofilaria immitis filarial skin test (Sawada) antigen in Wuchereria bancrofti filariasis. 1980. Am. J. Trop. Med. Hyg. 29:809-814.

21. Carvalho, E. M., R. Badaro, S. G. Reed, T. C. Jones, and W. D. Johnson, Jr. 1985. Absence of gamma interferon and interleukin 2 production during active visceral leishmanisis. J. Clin. Invest. 76:2066-2069.

22. Ojo-amaize, E. A., L. S. Salimonu, A. I. O. Williams, O. A. O. Akinwolere, R. Shabo, G. V. Alm, and H. Wigzell. 1981. Positive correllation between degree of parasitiemia, interferon titers, and natural killer cell activity in plasmodium falciparum-infected children. J. Immunol. 127:2296-3000.

23. Mohagheghpour, N., R. H. Gelber, H. W. Larrick, D. T. Sasaki, 
P. J. Brennan, and E. G. Engelman. 1985. Defective cell-mediated immunity in leprosy: failure of $\mathrm{T}$ cells from lepromatous leprosy patients to respond to Mycobacterium leprae is associated with defective expression of interleukin 2 receptors and is not reconstituted by interleukin 2 . J. Immunol. 135:1443-1449.

24. Hamilton, R. G., R. Hussain, and E. A. Ottesen. 1984. Immunoradiometric assay for detection of filarial antigens in human serum. J. Immunol. 133:2237-2242.

25. Forsyth, K. P., R. Spark, J. Kazura, G. V. Brown, P. Peters, P. Heywood, S. Dissanayake, and G. F. Mitchell. 1985. A monclonal antibody-based immunoradiometric assay for detection of circulating antigen in Bancroftian filariasis. J. Immunol. 134:1172-1177.

26. Sim, B. K., B. H. Kwa, and J. W. Mak. 1984. The presence of blocking factors in Brugia malayi microfilaremic patients. Immunology. 52:411-416.

27. Weil, G. J., R. Hussain, V. Kumaraswami, S. P. Tripathy, K. S. Phillips, and E. A. Ottesen. 1983. Prenatal allergic sensitization to helminth antigens in offspring of parasite-infected mothers. J. Clin. Invest. 71:1124-1129.

28. Dissanayake, S., L. V. K. DeSilva, and M. M. Ismail. 1980. IgM antibodies to filarial antigens in human cord blood. Possibility of transplacental infection. Trans. R. Soc. Trop. Med. Hyg. 74:541-544.
29. Kaplan, G., D. E. Weinstein, R. M. Steinman, W. R. Levis, U. Elvers, M. E. Patarroyo, and Z. A. Cohn. 1985. An analysis of in vitro T cell responsiveness in lepromatous leprosy. J. Exp. Med. 162:917929.

30. Linker-Israel, M., A. C. Bakke, F. P. Quismorio, and D. A. Horwitz. 1985. Correction of interleukin 2 production in patients with systemic lupus erythematosus by removal of spontaneously activated suppressor cells. J. Clin. Invest. 75:762-768.

31. Morimoto, C., N. L. Letvin, J. A. Distasio, W. R. Aldrich, and S. F. Schlossman. 1985. The isolation and characterization of the human suppressor inducer T cell subset. J. Immunol. 134:1508-1515.

32. Fanning, M., and J. W. Kazura. 1983. Genetic association of murine susceptibility to Brugia malayi microfilaremia. Parasite Immunol. 5:305-316.

33. Ottesen, E. A., N. R. Mendell, J. M. MacQueen, P. F. Weller, D. B. Amos, and F. E. Ward. 1981. Familial predisposition to filarial infection-not linked to HLA-A or -B locus specificities. Acta Trop. 38: 205-216.

34. Lamb, J. R., B. J. Skidmore, N. Green, J. M. Chiller, and M. Feldmann. 1983. Induction of tolerance in influenza virus-immune $T$ lymphocyte clones with synthetic peptides of influenza hemagglutinin. J. Exp. Med. 157:1434-1440. 